\title{
GCU
}

Glasgow Caledonian

University

University for the Common Good

\section{Consensus statement on bladder training and bowel training}

Booth, Jo; Bliss, Donna

Published in:

Neurourology and Urodynamics

DOI:

$10.1002 /$ nau. 24345

Publication date:

2020

Document Version

Author accepted manuscript

Link to publication in ResearchOnline

Citation for published version (Harvard):

Booth, J \& Bliss, D 2020, 'Consensus statement on bladder training and bowel training', Neurourology and Urodynamics, vol. 39, no. 5, pp. 1234-1254. https://doi.org/10.1002/nau.24345

\section{General rights}

Copyright and moral rights for the publications made accessible in the public portal are retained by the authors and/or other copyright owners and it is a condition of accessing publications that users recognise and abide by the legal requirements associated with these rights.

Take down policy

If you believe that this document breaches copyright please view our takedown policy at https://edshare.gcu.ac.uk/id/eprint/5179 for details of how to contact us. 


\section{Consensus Statement on Bladder Training and Bowel Training}

International Continence Society Nursing Committee

Chairs: Jo Booth PhD RN and Donna Bliss PhD, RN, FGSA, FAAN

Corresponding author:

Jo Booth, Professor of Rehabilitation Nursing,

Glasgow Caledonian University, Cowcaddens Road, Glasgow, UK

Tel +44 1413318635 email: jo.booth@gcu.ac.uk

Donna Z. Bliss, Professor and School of Nursing Foundation Professor of Nursing Research, University of Minnesota School of Nursing

email: bliss@umn.edu;

Short title: Bladder Bowel Training Consensus

Word count: 2407 words - text only

\section{Acknowledgements:}

On behalf of the ICS Nursing Committee the Chairs would like to thank the members of the Project Working Group and the members of the Consultation Group for their contributions to this Consensus Statement:

Project Working Group: Sharon Eustice; Kathleen Hunter; Joan Ostaszkiewicz.

Consultation Group: Alison Bardsley; Nikki Cotterill; Joanne Dean; Veerle Decalf; Tamara Dickinson; Sandra Engberg; Veronika Geng; Veronica Haggar; Amy Hunter; Lisa Krabbenhoft; Yuan-Mei Liao; Katherine Moore; Angela Rantell; Joanne Robinson; Alyson Sweeney; Janie Thompson; Susanne Vahr; Mary Wilde; Debbie Yarde. 


\section{Abstract}

\section{Aim}

This consensus statement synthesises evidence to guide healthcare professionals on promoting consistent, cohesive and achievable bladder training for people with overactive bladder/urgency urinary incontinence and bowel training for those with urgency faecal incontinence.

\section{Methods}

The Consensus Statement on Bladder and Bowel Training was developed by a subgroup of the International Continence Society Nursing Committee and an expert panel, who formed a virtual Consultation Group. Review of published research, expert opinion articles, policy statements, and voluntary professional group information identified existing recommendations, from which statements were formulated and organised. A modified Delphi process was used to reach consensus on each statement, involving three rounds of virtual consultation. Consultation Group members indicated agreement/disagreement with each statement. Statements, or changes, were accepted when consensus was reached, defined as agreement by $80 \%$ of the Consultation Group.

\section{Results}

No universal definition of bladder training or bowel training was found, therefore a consensus definition was developed and agreed for each. Limited high quality studies of bladder training were identified and no studies investigating the use or effectiveness of bowel training for urgency faecal incontinence in adults. Broadranging evidence suggests both types of training should include four elements, 
personalised to individual need and situation: information and education; a prescribed voiding/evacuation regimen based on individually identified patterns of bladder or bowel functioning; progression of voiding/evacuation regimen; ongoing support and reinforcement.

\section{Conclusions}

These consensus statements will support healthcare practitioners to design and deliver consistent bladder and bowel training. Improved evidence on mechanisms and effectiveness is needed to inform practice.

Keywords:

Bladder training; bowel training; behavior therapy; urinary incontinence; bowel dysfunction 


\section{Introduction}

Clinical guidelines across the world recognise bladder training $[1,2,3,4]$ as a first line intervention for lower urinary tract symptoms, including urgency urinary incontinence and bowel training as a first line intervention for urgency faecal incontinence in adults $[5,6]$. Healthcare practitioners involved in promoting continence and managing bladder/bowel dysfunction recommend these interventions regularly in practice. Bladder and bowel training are considered to be safe forms of therapy $[1,3,7,8]$ and may be implemented in a variety of care settings including community-based clinics, home care, and rehabilitation and aging care institutions based on patient ability and motivation and symptom-reports, without the need for extensive or invasive diagnostic investigations [2,3]. Evidence for effectiveness of bladder training suggests it may be helpful for treatment of urinary incontinence $[2,3,9]$ and that overactive bladder symptoms (urinary urgency and commonly frequency, nocturia, urgency incontinence) improve in 57-87\% and resolve in 12 $73 \%$ of cases [10]. There is currently no robust evidence on the effectiveness of bowel training for urgency faecal incontinence although observational studies have examined effects of individual parts of a bowel training program (i.e. diet advice, methylcellulose fibre) on urgency faecal incontinence [11] and differences in anorectal manometry and endoanal ultrasound measures in women with urgency versus passive faecal incontinence [12]. In practice, protocols vary considerably [13] and published reports provide only limited descriptions of the actual intervention content and delivery methods used $[14,15]$. Therefore, healthcare practitioners may find it challenging to access information on how to support people with these types of bladder or bowel dysfunction and effectively implement bladder training or bowel training programmes. 


\section{Aim}

This statement synthesises evidence from a range of sources to offer practical guidance to promote consistent, cohesive and achievable bladder training for people with overactive bladder syndrome/urgency urinary incontinence or bowel training for those with urgency faecal incontinence or defaecation urgency.

\section{Method of statement development}

The Consensus Statement was developed by a Project Working Group, a sub-group of the ICS Nursing Committee and a virtual Consultation Group. The ICS Nursing Committee was the overseeing steering group. The five members of the Project Working Group (JB, DB, JO, KH, SE) conducted a narrative review of published research evidence, expert opinion articles, clinical guidelines, policy statements, and information from voluntary professional groups. The information used was gathered from a broad range of sources to identify existing or previous practice recommendations from initiatives at local and national levels, incorporating qualitative as well as quantitative work. Structured searches for relevant research were conducted in PubMed, CINAHL, EMBASE, Cochrane Library, using Cochrane Incontinence Group topic search terms including: urinary incontinence, bladder instability/irritability/hyperreflexia, overactive bladder, behavioral intervention and bladder (re)training. Due to the challenge of identifying studies when a low yield was expected, the search for bowel training was conducted by a biomedical librarian. Search terms included ((anal or anorectal* or bowel* or faecal* or fecal* or rectal* or stool*) $^{\star}$ adj4 (continen* or incontinen**)).mp., (bowel and (habit* or management or program* or training or retraining)).mp. Given the anticipated low number of returns, there were no date limits applied, but searches were limited to adults and articles published in English. Searches for guidelines included relevant societies such as the 
European Urological Association, American Urological Association, Wound, Ostomy and Continence Nurses Society, American Society of Colon and Rectal Surgeons, American Gastroenterological Association, NICE Guidance, and the International Continence Society. The most recent International Consultation on Incontinence $6^{\text {th }}$ Edition $[2,5]$ was consulted. Other sources were identified in grey literature using search engines such as Google, Opengrey and relevant charity/voluntary organisation websites. Documents and materials used in practice by members of the Nursing Committee were also collated.

One member of the Project Working Group (JB) took the role of reading, sifting and formulating the evidence into statements, which the other members of the Project Working Group refined to construct the first version of the consensus statements to be sent to the virtual Consultation Group. The organization of the statements was modeled according to steps of the nursing process $[16,17]$ : assessment, planning, intervention and evaluation (See Appendix 1 and 2). A similar process is used as a healthcare approach by other types of healthcare practitioners. The statements are derived from the best available evidence, including expert opinion at the time they were produced, recognising that levels and types of evidence vary. The procedure used to reach consensus about each statement was based on the Delphi method and is outlined in the flowchart below (See Figure 1). In brief, 20 nurse members of ICS were recruited by the ICS office staff to serve as the virtual Consultation Group. The Consultation Group submitted curriculum vitae that were reviewed to support their expertise on the topic. The Consultation Group reviewed the statements developed by the Project Working Group and emailed suggested changes to the ICS office staff. Staff removed information identifying the person proposing the change, before forwarding the information to the Project Working 
Group. The Project Working Group incorporated the suggested changes to the statements into the document that was returned to the Consultation Group by the ICS staff. The Consultation Group emailed their votes for agreeing or disagreeing with statements or changes to the ICS office staff. This procedure was repeated three times. Statements or changes were accepted when consensus was reached, defined as agreement by $80 \%$ of the Consultation Group. For information, a glossary of the standardized ICS definitions used in constructing these consensus statements is provided as a supplemental file.

Insert Figure 1 here

Figure 1. Consensus statement development flowchart

\section{Consensus Statement on Bladder Training}

\section{Definition of bladder training:}

Bladder training is a broad term, encompassing bladder retraining, bladder discipline, bladder re-education and bladder drill [2]. There is currently no universally agreed definition of bladder training for adults, although the 2016 International Consultation on Incontinence describes bladder training (Chap 12, p.86) as 'a program of patient education, along with a scheduled voiding regimen with gradually adjusted voiding intervals. Specific goals are to correct faulty habit patterns of frequent urination, improve control over bladder urgency, prolong voiding intervals, increase bladder capacity, reduce incontinent episodes and restore patient confidence in controlling bladder function' [2]. Bladder training is considered to be a form of behaviour modification, (defined by the International Continence Society (ICS) as 'the analysis 
and alteration of the relationship between the patient's symptoms and his or her environment for the treatment of maladaptive voiding patterns, which may be achieved by modification of the behaviour and/or environment of the patient' [18]). However recent bladder training developments have placed increasing emphasis on the importance of cognitive and psychological aspects that target beliefs and perceptions in order to impact behaviour [20].

Based on the literature reviewed for the purposes of this Consensus Statement the following definition of bladder training was developed:

Bladder training is an intervention that actively supports a motivated person, without significant cognitive or physical impairment, with an overactive bladder or urgency urinary incontinence, to make lifestyle and behavioural changes to regain bladder control through education, progressively increasing voiding intervals, use of urgency suppression techniques and positive reinforcement of effort and success.

\section{How bladder training works}

The mechanism of action of bladder training is not fully understood [2]. It arose from the theoretical premise that abnormal voiding habits could be altered by modifying an individual's behaviour. The purpose of bladder training is to restore a normal voiding pattern by progressively lengthening the interval between voids. People with bladder dysfunction are taught to void at regular intervals throughout the day and to otherwise suppress the urge to void using strategies such as distraction and relaxation [14]. It is hypothesised that by repeatedly suppressing the urge to void, the 
person's functional bladder capacity will increase and this, in turn, will lead to a reduction in urinary frequency and the urge to void $[2,20]$. Urgency suppression techniques help the person achieve bladder control by diverting their attention away from the urgency sensation using competing mental activities. Relaxation techniques aim to reduce anxiety and feelings of panic. It is hypothesised that deep breathing reduces the intensity of the urgency sensation and relaxes the detrusor muscle [20]. Together these urge suppression techniques are thought to enable improved cortical bladder control by inhibition of involuntary detrusor contractions; improved urethral closure during bladder filling and control of afferent sensations.

In order to perform bladder training, patients need to have the mental and physical capacity to: i) identify the urge to void; ii) understand how the bladder functions, iii) rapidly contract their pelvic floor muscles; and/or iv) apply distraction techniques to suppress the urge to void and (v) defer voiding $[2,14]$. Thus, education and coaching are key components of the intervention. Additionally, since positive outcomes rely on active client participation, motivation and the cognitive/physical ability to adhere to a progressive schedule are also essential [22].

Bladder training differs from scheduled voiding programmes, such as timed voiding or prompted voiding in so far as it includes cognitive and psychological components $[23,24]$. It is thought that bladder training, through operant learning techniques, improves cortical control over the lower urinary tract $[21,25]$. Operant learning is brought about by the positive feedback created by successful urge suppression and longer voiding intervals and conscious recognition by the person of their improved bladder control. However, based on the idea that frequency is a habit that becomes 
a precursor to urgency and drives it, the role of emotion in the development of urgency is increasingly becoming the target of intervention [19]. The roles of other cognitive contributors, including self-monitoring, education/information, positive reinforcement, follow up, as well as health behavioural change theories are recognised, but have yet to be fully explored in light of bladder training theories.

Insert table 1 here

\section{Table 1 - Consensus Statement on Bladder Training}

The Consensus Statement on Bladder Training is presented in table 1, however the full document, which includes supporting evidence for each statement, as well as suggestions on demonstrating its use in practice, is provided as appendix 1.

\section{Consensus Statement on Bowel Training \\ Definition of bowel training:}

The term bowel training encompasses bowel retraining and bowel re-education, a form of behaviour modification designed to restore bowel continence by changing a person's behaviour and/or environment [18]. There is currently no universally agreed definition of bowel training so based on the literature reviewed for this Consensus Statement the following definition of bowel training was developed:

Bowel training is an intervention that actively enables a motivated person, without significant cognitive or physical impairment, with urgency faecal incontinence or defaecation urgency to make lifestyle and behavioural changes to regain a controlled response to urgency and a satisfactory pattern of defaecation through education, progressively increasing intervals between 
defecations, use of urgency suppression techniques, and positive reinforcement of effort and success.

\section{How bowel training works}

Similar to bladder training the mechanism of bowel training is poorly understood and robust evidence on approaches to bowel training and effectiveness of intervention is urgently needed [2]. There are physical and psychological elements in a bowel training programme that aim to establish predictable, regular patterns of bowel elimination, using personalised education and support to adhere to routines [2]. The functional integrity of the external anal sphincter is a key focus because the external anal sphincter is a continuation of the striated puborectalis muscle and therefore it is voluntarily controlled and can be trained. Pelvic floor muscle exercises to strengthen the external anal sphincter, improve contraction speed, endurance and sphincter coordination are an important component of bowel training [26]; however, there is no evidence on the most effective protocol to achieve improvements or sustain the effects [7].

The psychological components of bowel training aim to reduce anxiety and panic associated with sudden onset bowel urgency, to enable the person to develop and maintain a sense of control, which will allow them to reach a toilet prior to any leakage occurring [27]. These include general anxiety reduction techniques (including stopping, focusing, deep breathing and positive self-talk). Establishing a routine for defaecation and ensuring the bowel is fully emptied are important parts of the programme, as they will increase the predictability of bowel activity and therefore reduce associated anxiety [26]. As with bladder training, patients undertaking bowel 
training need to have the mental and physical capacity to: i) identify the urge to defeacate; ii) understand how their bowel functions, iii) rapidly contract their pelvic floor muscles; and/or iv) apply relaxation and distraction techniques to suppress the urge to defeacate and (v) prolong intervals between defaecations [2]. Thus, education and coaching are key components of the intervention. Individual motivation to participate, as well as the cognitive and physical ability to adhere to a progressive training schedule, are considered as essential to a positive outcome for bowel training as they are for bladder training [22].

Insert Table 2 here

\section{Table 2 - Bowel Training Consensus Statement}

The Consensus Statement on Bowel Training is presented in table 2, however the full document, which includes supporting evidence for each statement as well as suggestions on demonstrating its use in practice, is provided as appendix 2.

\section{Potential Use}

The Consensus Statement on Bladder and Bowel Training can be used by nurses and other healthcare professionals in developing and implementing a plan of care for promoting continence with adults. The document offers expert consensus to fill a gap in current knowledge with the aim of supporting bladder and bowel continence nursing care and improving patient outcomes. The document highlights the sparse evidence base for bladder and bowel training, and it is hoped that it will stimulate 
research to provide further evidence to inform its content and improve its applicability and effectiveness. 


\section{References}

1. Nambiar AK, et al. EAU Guidelines on Assessment and Nonsurgical Management of Urinary Incontinence. Eur Urol, 2018 https://doi.org/10.1016/i.eururo.2017.12.031

2. Dumoulin $\mathrm{C}$, Adewuyi $\mathrm{T}$, Booth $\mathrm{J}$ et al. Adult conservative management (Chapter 12). In: Abrams P, Cardozo L, Wagg A, Wein A (eds). Incontinence $6^{\text {th }}$ Edition: Proceedings from the $6^{\text {th }}$ International Consultation on Incontinence, Tokyo, September 2016. Bristol, UK: International Continence Society; 2017.

3. Gormley EA, Lightner DJ, Burgio KL et al. Diagnosis and Treatment of Overactive Bladder (Non-neurogenic) in Adults: AUA/SUFU Guideline. 2019.

4. National Institute for Clinical Excellence. Urinary incontinence and pelvic organ prolapse in women: management. Clinical guideline 123, 2019 https://www.nice.org.uk/guidance/cg123

5. Bliss DZ, Toshiki M, Berghmans B et al. Assessment and conservative management of faecal incontinence and quality of life in adults (Chapter 16). In: Abrams P, Cardozo L, Wagg A, Wein A (eds). Incontinence $6^{\text {th }}$ Edition: Proceedings from the $6^{\text {th }}$ International Consultation on Incontinence, Tokyo, September 2016. Bristol, UK: International Continence Society, 2017.

6. National Institute for Clinical Excellence. Faecal incontinence in adults: management. Clinical guideline 49 https://www.nice.org.uk/guidance/cg49

7. Norton C, Cody JD. Biofeedback and/or sphincter exercises for the treatment of faecal incontinence in adults. Cochrane Database of Systematic Reviews 2012, Issue 7. Art. No.: CD002111. DOI:10.1002/14651858.CD002111.pub3. 
8. Yoon HS, Song HH, Ro YJ. A comparison of effectiveness of bladder training and pelvic muscles exercise on female urinary incontinence. International Journal of Nursing Studies 2003;40: 45-50.

9. Wallace SA, Roe B, Williams K, Palmer M. Bladder training for urinary incontinence in adults. Cochrane Database of Systematic Reviews 2004, Issue 1. Art. No.: CD001308. DOI: 10.1002/14651858.CD001308.pub2.

10. Wyman JF. Treatment of urinary incontinence in men and older women. The evidence shows the efficacy of a variety of techniques. American Journal of Nursing 2003;103(suppl):26-35.

11. Ribas $\mathrm{Y}$, Munoz-Duyos A. Conservative treatment of severe defecatory urgency and fecal incontinence: minor strategies with major impact. Techniques in Coloproctology 2018; 22:673-682.

\section{https://doi.org/10.1007/s10151-018-1855-5}

12. Pahwa AK, Khanijow KD, Harvie HS, Arya LA, Andy UU. Comparison of Patient Impact and Clinical Characteristics Between Urgency and Passive Fecal Incontinence Phenotypes. Female Pelvic Med Reconstr Surg 2018;00: 00-00.

13. Corcos J, Przydacz M, Campeau L, Witten J, Hickling D, Honeine C et al. CUA guideline on adult overactive bladder. Can Urol Assoc J 2017;11(5):

\section{E142-73. http://dx.doi.org/10.5489/cuaj.4586}

14. Wyman JF, Burgio KL, Newman DK. Practical aspects of lifestyle modifications and behavioural interventions in the treatment of overactive bladder and urgency urinary incontinence. International Journal of Clinical Practice 2009;63 (8):1177-1191. 
15. Payne C. Behavioral therapy for overactive bladder. Urology 2000; 55 (suppl 5A: 3-6).

16. American Nurses Association. The Nursing Process.

https://www.nursingworld.org/practice-policy/workforce/what-is-nursing/thenursing-process/

17. Stonehouse, DP. Understanding the nursing process. University of Salford. http://usir.salford.ac.uk/46573/

18. Abrams P, Cardozo L, Fall M et al. The standardization of terminology of lower urinary tract function: Report from the Standardisation Sub-committee of the ICS. Neurourology and Urodynamics 2002; 21:167-178.

19. McAchran S. The mind-bladder connection: Current understanding of the relationship of psychological stress and overactive bladder symptoms. Curr Bladder Dysfunc Rep 2014; 9:145-150.

20. Burgio KL. Influence of behaviour modification on overactive bladder. Urology 2002; 60 (Suppl 5A): 72-77.

21. Fantl JA, Wyman JF, McClish DK, Harkins S, Elswick R, Taylor J et al. Efficacy of bladder training in older women with urinary incontinence. JAMA 1991;265 (5): 609-613.

22. Hadley EC. Bladder Training and Related Therapies for Urinary Incontinence in Older People. JAMA. 1986;256(3):372-379.

doi:10.1001/jama.1986.03380030074031

23. Burgio KL. Update on behavioural and physical therapies for incontinence and overactive bladder: The role of pelvic floor muscle training Curr Urol Rep $2013 ; 14: 457-464$. 
24. Roe B, Milne J, Ostaszkiewicz J, Wallace S. Systematic reviews of bladder training and voiding programmes in adults: a synopsis of findings on theory and methods using meta-study techniques. Journal of Advanced Nursing 2007; 57(1): 3-14.

25. Wyman JF, Fantl JA, McClish DK et al. Comparative efficacy of behavioural interventions in the management of female urinary incontinence. Am J Obstet Gynecol 1998; 179:999-1007.

26. Bates F, Bliss DZ, Bardsley A, Yeung W. Management of fecal incontinence in community-living adults. Chap 6, p111. In: Bliss DZ (Ed) - Management of Fecal Incontinence for the Advanced Practice Nurse. Springer Int Pub AG, 2018.

27. Bliss DZ, Norton C. Conservative management of fecal incontinence: An evidence-based approach to controlling this life-altering condition. American Journal of Nursing 2010;110 (9) Sep:30-40.

28. Elser DM, Wyman JF, McClish DK et al. The effect of bladder training, pelvic floor muscles training or combination training on urodynamic parameters in women with urinary incontinence. Neurourology and Urodynamics 1999; 18:427-436.

29. Subak L, Queesnberry C, Posner S, et al. The effect of behavioral therapy on urinary incontinence: a randomized controlled trial. Obstetrics and Gynecology 2002; 100:72- 78.

30. Wyman JF, Fantl A. Bladder training in ambulatory care management of urinary incontinence. Urol Nursing 1991; 11:11-17.

31. Dowd T, Dowd T. A cognitive therapy approach to promote continence J Wound Ostomy Continence Nurs 2006; 33:63-68. 
32. Ajzen I. The theory of planned behavior. Organizational Behavior and Human Decision Processes 1991; 50:179-211.

33. Aston B, Sheehan L. Goal setting for faecal incontinence: A patient-centred approach. Gastrointestinal Nursing 2010; 8(3):18-24.

34. Deci EL, Ryan RM. The "what" and "why" of goal pursuits: Human needs and the self-determination of behavior. Psychological Inquiry 2000;11: 227-268.

35. Diokno AC, Sampselle CM, Herzog AG et al. Prevention of urinary incontinence by behavioral modification programme: a randomized controlled trial among older women in the community. J Urol 2004; 171:1161-4.

36. Burgio KL, Whitehead WE, Engel BT. Urinary incontinence in the elderly: bladder-sphincter biofeedback and toileting skills training. Ann Intern Med; 1985; 104:507-515.

37. Lukacz E, Sampselle C, Gray M, et al. A healthy bladder: a consensus statement, Int J Clin Pract 2011; 65(10):1026-1036.

38. Jarvis GJ, Millar DR. Controlled trial of bladder drill for detrusor instability. British Medical Journal 1980; 281(6251):1322- 1323.

39. Majumdar A, Hassan I, Saleh et al. Inpatient bladder retraining: is it beneficial on its own? Int Urogynecol J 2010; 21:657-663.

40. Newman D, Borello-France D, Sung V. Structured behavioral treatment research protocol for women with mixed urinary incontinence and overactive bladder symptoms. Neurourology Urodynamics 2018 Jan;37(1):14-26. DOI: 10.1002/nau.23244. Epub 2017 May 2.

41. Lee HE, Oh SJ. The effectiveness of bladder training in overactive bladder. Curr Bladder Dysfunc Rep 2014; 9:63-70. 
42. Burgio KI, Locher JL, Goode PS et al. Behavioral versus drug treatment for urge incontinence in older women: a randomized clinical trial. JAMA 1998; $23 ; 1995-2000$.

43. Burgio KL, Goode PS, Locher JL et al. Behavioral training with and without biofeedback in the treatment of urge incontinence in older women: a randomized controlled trial. JAMA 2002; 288:2293-9.

44. Burgio KL, Goode PS, Johnson TS et al. Behavioral Versus Drug Treatment for Overactive Bladder in Men: The Male Overactive Bladder Treatment in Veterans (MOTIVE) Trial. Journal of the American Geriatrics Society $2011 ; 59: 12: 2209$.

45. Dougherty MC, Dwyer JW, Penedrgast JF, Boyington AR, Tomlinson BU, Coward RT et al. A randomised trial of behavioural management for continence with older rural women. Research in Nursing and Health 2002; 25(1):3-13.

46. Richard AA, Shea K. Delineation of self-care and associated concepts. J Nurs Scholar. 2011; 43 (3):255-64.

47. Freeman A, Menees S. Fecal Incontinence and Pelvic Floor Dysfunction in Women: A Review. Gastroenterology Clinics of North America 2016; 45(2): 217-37.

48. Doughty D, Jenson LL Chapter 15. Assessment and management of the patient with fecal incontinence and related bowel dysfunction. In: Doughty D (Ed), Urinary and fecal incontinence: current management concepts ( $3^{\text {rd }}$ Ed), St Louis, MI: Mosby Elsevier; 2006, 457-489p.

49. Stackhouse K. FINCH: a four stage approach to treating constipation and faecal incontinence. Gastrointestinal Nursing 2016;14 (10):18-24. 
50. Harari D et al. Treatment of constipation and fecal incontinence in stroke patients: randomised controlled trial. Stroke 2004; 35(11):2549-2555.

51. Norton $\mathrm{C}$ et al. A randomised controlled trial for fecal incontinence. Gastroenterology 2003;125 (5):1320-9.

52. Sakakibara R, Tsunoyama K, Hosoi H et al. Influence of Body Position on Defecation in Humans. LUTS 2010; 2:16-21.

53. Bartlett L, Sloots K, Nowak M, Ho Y. Impact of relaxation breathing on the internal sphincter in patients with faecal incontinence. The Australian and New Zealand Continence Journal 2012;18(2):38-45.

54. Stokes G. Psychological approaches to bowel care in older people with dementia. In: Potter J et al (eds). Bowel care in older people: research and practice. London Clinical Effectiveness and Evaluation Unit, Royal College of Physicians; 2002. 97-110p.

55. Bliss DZ, Savik K, Jung HJG, Whitebird R, Lowry A, Sheng X. Dietary fiber supplementation for fecal incontinence: A randomized clinical trial. Research in Nursing and Health, 2014;37(5):367-378.

56. Markland AD, Burgio KL, Whitehead WE, Richter HE, Wilcox CM, Redden DT, et al. Loperamide Versus Psyllium Fiber for Treatment of Fecal Incontinence: The Fecal Incontinence Prescription (Rx) Management (FIRM) Randomized Clinical Trial. Dis Colon Rectum 2015; 58:983-993.

57. Bliss DZ, Jung HJ, Savik K, Lowry A, LeMoine M, Jensen L, Werner C, Schaffer K. Supplementation with dietary fiber improves fecal incontinence. Nursing Research, 2001;50: 203-213. 


\section{Consensus Statement on Bladder Training}

\section{Assessment}

Adults with urinary incontinence or other lower urinary tract dysfunction are assessed by a healthcare practitioner for lifestyle, risk factors and quality of life to ensure the type of bladder dysfunction is identified:

0 urinary incontinence $(\mathrm{UI})$ - urgency $\mathrm{UI}$, mixed $\mathrm{UI}$

0 overactive bladder $(\mathrm{OAB})$ or other storage lower urinary tract symptoms

and that the person:

- is suitable for bladder training and potentially will benefit.

- has the functional ability to use the toilet either independently or with assistance

- is cognitively able to participate

- is motivated to undertake and adhere to a personalised bladder training programme

- has realistic expectations of treatment

- has ability to voluntarily contract pelvic floor muscles

\section{Planning}

The person's goals for bladder training are established with the healthcare practitioner. e.g., a reduction in the frequency and severity of symptoms; the ability to sleep at night without going to the toilet; the ability to go out and socialise; reduced carer impact etc.

> The practitioner develops or structures the person's bladder training programme in collaboration with them, taking into account their personal goals and the following factors, before commencing the programme:

- the frequency of voiding and voiding intervals

- duration of bladder training the person will practice before attempting to increase the voiding interval

- whether the person prefers a standardised bladder training schedule or one that is individually tailored

- how long the person will attempt to suppress the urge to void when urgency is experienced (e.g. 5, 10, 15 or 30 minutes, or until urgency subsides)

- the duration of the full bladder training programme in weeks

- the indicators of improvement and readiness to progress (e.g. reduction in number of incontinence episodes, urge reduction, demonstrated commitment to the schedule)

- the types of urgency suppression techniques the person will use

- the method the person will use to self-monitor their progress e.g. bladder diaries, measured voided volumes

\section{Intervention}

$>$ The healthcare practitioner ensures the bladder training programme is structured and supervised.

- The bladder training programme duration will vary according to the person's progress and goals but should be at least 6 weeks.

- Healthcare practitioners should review clients on a regular basis and adjust the mode and frequency of contact according to their professional judgement and the person's goals and preferences. The degree of reinforcement (coaching) patients require will vary.

- Follow-up support to maintain effects of bladder training should be provided, in accordance with the person's goals and preferences.

$>$ The healthcare practitioner provides adults undertaking bladder training with verbal and written information and education on:

o what constitutes a healthy bladder, including its function, anatomy and potential susceptibility to dysfunction

$0 \quad$ what happens to the bladder in overactive bladder syndrome/urinary incontinence

o their individual bladder function and patterns, including anticipatory/'just in case' voiding habits and incontinence episodes (based on bladder diary)

o effects of current medication, diet, fluids and caffeine on bladder function

o how to self-monitor symptoms and interpret their bladder diary

o purpose of bladder training

o how bladder training works

0 the rise and de-escalation of the sensation of urgency, sometimes known as the 'urge wave' [36]

0 the staged approach to bladder training

0 the need for active involvement, commitment and ongoing motivation

o psychological strategies to support success

0 realistic expectations about the efforts required and the potential challenges

o expected outcomes

An initial bladder training programme and voiding intervals are agreed and implemented based on the person's baseline voiding diary information and individual goals.

Bladder training is usually implemented during waking hours only 
Voiding intervals are set in accordance with the person's preference for a standardised bladder drill or individually tailored bladder training schedule:

o If standardised a fixed (or pre-determined) voiding schedule of half-hourly or hourly voids is implemented for an agreed time period. Once achieved, this schedule is increased by a pre-determined duration of 5, 10, 15 or 30 minutes at each progression point.

o If tailored, individualised voiding intervals are implemented based on the person's average voiding interval calculated from their voiding diary. Progression time to prolong voiding intervals is negotiated on an individual basis e.g. increase by $5,10,15,30$ minutes per week.

> The health care practitioner regularly reviews the bladder training programme with the person to determine specific voiding interval progression in line with their goals. Voiding diary data and self-report inform this process.

New continence skills are developed in the form of personalised urge suppression strategies.

Urge suppression or deferment involves:

o relaxation - the person is instructed to stop, sit down if possible, relax their whole body, in particular their abdomen and focus on slow, controlled breathing.

o pelvic floor muscle contraction - the person completes 5-8 fast pelvic floor muscle contractions, without increasing their intra-abdominal pressure.

o distraction techniques - mental activities that demand cognitive attention and concentration are used to distract the person from their sensation of urgency and desire to void.

o The individual should decide what will work for them. Examples include: counting backwards from 100 in 7's, identifying different girl's names through the alphabet, singing out loud, word searches/crossword puzzles, digital games, reading, making lists.

o Use of self-affirming statements such as 'I can control my bladder' and 'I don't have to go now'

o apply perineal pressure - sit on a hard surface, rolled towel or stimulate foot sensation using toe curls and heel pressure until the urgency subsides.

Urgency sensation may subside within 1-2 minutes.

When urgency is controlled, and if voiding is permitted according to the bladder training programme, the person is encouraged to walk to the toilet at a normal pace.

The healthcare practitioner positively reinforces the person's bladder control skills and improved and/or prolonged bladder control.

Individuals are actively encouraged and supported to:

o self-monitor their:

- relaxation capability and capacity to control their response to urgency and fear of incontinence episodes

- duration of urge suppression

- intensity of urgency sensations

- number of incontinence episodes

- $\quad$ reduction in negative voiding habits such as 'just in case' or anticipatory voiding

- $\quad$ progress toward achieving a normal bladder pattern

o self-determine their:

- $\quad$ progression time e.g. increasing urge suppression/voiding delay time

- decisions about when to increase their urge suppression/voiding delay time.

o self-affirm their:

- Use of personally meaningful self-coping statements such as 'I don’t have to go now; I can wait'; ‘I am in control of my bladder'

\section{Evaluation}

Regular contact between the person and the healthcare practitioner is made during the bladder training programme to review progress, assess adherence, provide positive reinforcement and adjust voiding programme/intervals. At the end of the bladder training programme a range of person-focused outcomes are assessed. These may include:

- $\quad$ perceptions of bladder condition and improvement

- influence of bladder on daily activities

- $\quad$ satisfaction with bladder training

- $\quad$ tolerability of bladder training and adherence

- $\quad$ frequency and severity of urgency and incontinence episodes

- $\quad$ improvements in lower urinary tract symptoms

- voiding interval changes

- lifestyle changes

- changes in quality of life

- change in body-worn absorbent product use 


\section{Consensus Statement on Bowel Training}

\section{Assessment}

Healthcare practitioners conduct an assessment of the person's bowel symptoms to ensure the cause and type of bowel dysfunction is identified prior to recommending a bowel training programme

Current lifestyle and risk factors for bowel dysfunction (e.g. aggravating foods, medication side effects) are assessed.

Underlying physiological abnormalities are excluded prior to recommending a bowel training programme The person's suitability to undertake bowel training is assessed including:

- $\quad$ potential for benefit

- functional ability to use the toilet/toilet aid

- cognitive capacity

- motivation to undertake and adhere to a personalised bowel training programme

- $\quad$ expectations of treatment

- $\quad$ ability to voluntarily contract pelvic floor muscles

\section{Planning}

The person's goals for bowel training are established with the healthcare practitioner, e.g., a reduction in the frequency and severity of symptoms; the ability to go out and socialise; reduced carer burden such as laundering soiled clothing and linens, decreased socialization and travel, cost of absorbent products, etc.

$>$ The practitioner develops or structures the person's bowel training programme in collaboration with them, taking into account the following factors before commencing the programme:

- frequency of defaecation

- duration of the full bowel training programme in weeks/months

- $\quad$ indicators of improvement

- $\quad$ types of urgency suppression techniques the person will use (where appropriate)

- $\quad$ methods to normalise and regulate stool consistency

- $\quad$ method the person will use to self-monitor their progress e.g. bowel diaries

- lifestyle changes

\section{Intervention}

The healthcare practitioner ensures the bowel training programme is structured and supervised. The programme duration will vary according to the person's progress and goals.

$>$ The healthcare practitioner provides adults undertaking bowel training with verbal and written information and education on:

- normal bowel function

- how faecal incontinence occurs

- factors affecting bowel functioning including diet and dietary fibre, fluids, smoking, exercise, psychological/emotional status and environment

- medication and laxatives

- $\quad$ purpose of bowel training and how it works

- the need for active involvement, commitment and ongoing motivation by the person

- $\quad$ psychological strategies to support success

- use of containment products during bowel training

- realistic expectations about the efforts required and the potential challenges

- $\quad$ expected outcomes

$>\quad$ The person's bowel diary (minimum 5-7 days) is interpreted jointly by the person and the healthcare practitioner to identify individual bowel function and patterns and align with agreed goals.

The healthcare practitioner offers the person a bowel training programme that includes information about:

- optimal time of day for defaecation

- $\quad$ frequency of defaecation attempts, e.g., daily, alternate days, three times per week

- optimal type and amount of food intake

- optimal type and amount of fluid intake

- $\quad$ individual advice on smoking cessation

- $\quad$ use of drugs, dietary fibre, or rectal irrigation for faecal incontinence; antidiarrheal drugs or stool bulking agents may be used to establish and maintain a normal stool consistency and frequency; laxatives, suppositories, enemas or transanal irrigation may be used to completely empty the rectum to avoid leakage

An external anal sphincter (EAS) and pelvic floor muscle exercise programme, tailored to the lifestyle and needs of the person is agreed with the healthcare practitioner. This will include specific exercises aimed at 
improving strength, speed and endurance of the external anal sphincter and pelvic floor muscle contraction and relaxation.

Concerns/anxieties affecting the person's psychological/ emotional state are actively screened for and managed.

The healthcare practitioner ensures the person can use effective defaecation techniques:

- correct positioning on the toilet - may involve use of footstools and leaning forward to increase hip flexion, straighten the anorectal angle, and ensure stability of sitting position.

- allowing sufficient time to fully empty bowel

- ensuring privacy and no interruptions

- $\quad$ attention to privacy and comfort measures e.g. toilet temperature, noise and odour reduction

The healthcare practitioner encourages the person to develop individualised urge suppression strategies:

When the person feels the urge to defeacate they are encouraged to suppress the urge using the techniques below until the sensation is reduced sufficiently to allow them to get to a toilet without rushing. Once they are in the toilet they are encouraged to wait for a minute or so before actually sitting on the toilet to open their bowels. They gradually increase the amount of time they wait before they use the toilet.

Urge suppression or deferment involves:

o relaxation - the person is advised to stop, relax their whole body, in particular their abdomen and focus on slow, controlled breathing.

o external anal sphincter and pelvic floor muscle_contraction - the person completes 5-8 fast contractions, without increasing their intra-abdominal pressure.

o distraction techniques - mental activities that demand cognitive attention and concentration will distract the person from their sensation of urgency and desire to evacuate. The individual should decide what will work for them (different techniques may be used at different times). Examples include: counting backwards from 100 in 7's (or 5's for older adults), identifying girl's names through the alphabet, singing out loud, word searches/crossword puzzles, digital games, reading, making lists.

o applying perineal pressure - sit on a hard surface, rolled towel

Bowel urgency sensation may subside within 1-2 minutes. When urgency is controlled, encourage person to walk to the toilet at a normal pace.

The healthcare practitioner positively reinforces the person's continence skills and improved and/or prolonged bowel control.

Individuals are actively encouraged and supported to:

o self-monitor their:

- $\quad$ perceived capability to relax - to stop what they are doing, take slow, deep breaths, relax their body especially their abdomen and not rush to the toilet until the urgency sensation has diminished

- duration of urge suppression

- intensity of urgency sensations

- number of faecal incontinence episodes

- reduction in negative defaecation habits such as prolonged or frequent toilet use

- progress toward achieving a normal bowel pattern

- lifestyle changes

o self-determine their:

- progression time e.g. increased urge suppression/delay time

- decisions about when to increase duration of their urge suppression/delay time.

0 self-affirm their:

o use of personally meaningful self-coping statements such as 'I don't have to go now; I can wait'; 'I am in control of my bowel'

\section{Evaluation}

Regular contact between the person and the healthcare practitioner is made during the bowel training programme to review progress, assess adherence, provide positive reinforcement and adjust schedules. At the end of the bowel training programme a range of person-focused outcomes are assessed. These may include:

o perceptions of bowel condition and any improvements/changes

o satisfaction with bowel training

o tolerability of bowel training processes and adherence to recommended programme

0 frequency and severity of bowel symptoms including urgency and incontinence episodes,

o defaecation intervals

o lifestyle changes

o quality of life 
o change in absorbent product use (e.g., decrease in number)

Table 2: Consensus Statement on Bowel Training 

practice

\section{Assessment}

Adults with urinary incontinence or other lower urinary tract dysfunction are assessed by a healthcare practitioner for lifestyle, risk factors and quality of life to ensure the type of bladder dysfunction is identified:

o urinary incontinence (UI) - urgency UI, mixed UI

o overactive bladder (OAB) or other storage lower urinary tract symptoms

and that the person:

- is suitable for bladder training and potentially will benefit.

- $\quad$ has the functional ability to use the toilet either independently or with assistance

- $\quad$ is cognitively able to participate

- $\quad$ is motivated to undertake and adhere to a personalised bladder training programme

- has realistic expectations of treatment

- has ability to voluntarily contract pelvic floor muscles
- $\quad$ Bladder training may be an effective first-line behavioural therapy for adults [28] (including older adults [29]) with urgency UI/ mixed UI: OAB symptoms resolved 12\%-73\%; OAB symptoms improved 57\%-87\% [10]

- Understanding of bladder function, the purpose of bladder training and the need to progressively increase the voiding interval are essential for bladder training to be effective [30]

- Active participation is essential to modify behaviour and develop central control over the bladder [31]

- Individual beliefs and expectations are fundamental to a person's behaviour and indicates their likely participation and adherence [32]
A complete assessment includes:

- Documented comprehensive individual assessment including lifestyle factors, (e.g., obesity, smoking, fluid and caffeine intake, etc.)

Voiding diary (minimum 72 hours) including measured volumes

- Diagnosed lower urinary tract disorder based on signs and symptoms or a urodynamic diagnosis

- Individual expectations of bladder training and lifestyle changes are documented.

\section{Planning}

The person's goals for bladder training are established with the healthcare practitioner. e.g., a reduction in the frequency and severity of symptoms; the ability to sleep at night without going to the toilet; the ability to go out and socialise; reduced carer impact etc.

The practitioner develops or structures the person's bladder training programme in collaboration with them, taking into account their personal goals and the following factors, before commencing the programme:

- the frequency of voiding and voiding intervals

- duration of bladder training the person will practice before attempting to increase the voiding interval

- $\quad$ whether the person prefers a standardised bladder training schedule or one that is individually tailored

- how long the person will attempt to suppress the urge to void when urgency is experienced (e.g. 5, 10, 15 or 30 minutes, or until urgency subsides)

- $\quad$ the duration of the full bladder training programme in weeks

- the indicators of improvement and readiness to progress (e.g. reduction in number of incontinence episodes, urge reduction, demonstrated commitment to the schedule)

- the types of urgency suppression techniques the person will use

- the method the person will use to selfmonitor their progress e.g. bladder diaries, measured voided volumes
- It is important for healthcare practitioners to assist individuals to set specific goals that are personal, and realistic [23]. Personal goals for bladder training may be different to goals set within the programme for symptom improvement, but both are important for effective planning and are part of the evaluation [33]

- Jointly agreeing on personal and programme goals supports engagement with the bladder training programme [14]. Working towards a specific goal improves motivation and performance $[33,34]$

- Daytime voiding intervals of 2.5 to 4 hours are recommended $[29,35]$
- $\quad$ Personal goals and specific progression criteria are documented in the bladder training plan.

- Review dates and end of bladder training programme dates are specified

\section{Intervention}

The health care practitioner ensures the bladder training programme is structured and supervised. The bladder training programme duration will vary according to the person's progress and goals but should be at least 6 weeks.
Regular practice of skills to maintain continence is essential to maintain performance [36]
- A documented bladder training plan, including mode and frequency of contact between person and healthcare practitioner 


\begin{tabular}{|c|c|c|c|}
\hline$>$ & $\begin{array}{l}\text { Healthcare practitioners should review clients on a } \\
\text { regular basis and adjust the mode and frequency } \\
\text { of contact according to their professional } \\
\text { judgement and the person's goals and } \\
\text { preferences. The degree of reinforcement } \\
\text { (coaching) patients require will vary. } \\
\text { Follow-up support to maintain effects of bladder } \\
\text { training should be provided, in accordance with the } \\
\text { person's goals and preferences. }\end{array}$ & $\begin{array}{l}\text { - Intensive supervision by a healthcare } \\
\text { practitioner improves the likelihood of positive } \\
\text { outcomes [2,25] } \\
\text { - Successful bladder training is structured and } \\
\text { involves frequent patient contact }[24,25] \\
\text { - Clinical guidelines, based on limited evidence } \\
\text { recommend a } 6 \text {-week minimum bladder } \\
\text { training programme duration }[3,4] \\
\text { - Follow up is essential [1]. Effectiveness of } \\
\text { bladder training may diminish after the } \\
\text { programme has ceased. }\end{array}$ & 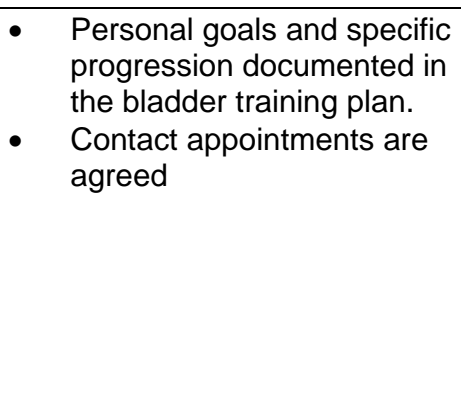 \\
\hline$>$ & $\begin{array}{c}\text { The health care practitioner provides adults } \\
\text { undertaking bladder training with verbal and written } \\
\text { information and education on: } \\
\text { o what constitutes a healthy bladder, including } \\
\text { its function, anatomy and potential } \\
\text { susceptibility to dysfunction } \\
\text { o what happens to the bladder in overactive } \\
\text { bladder syndrome/urinary incontinence } \\
\text { their individual bladder function and patterns, } \\
\text { including anticipatory/'just in case' voiding } \\
\text { habits and incontinence episodes (based on } \\
\text { bladder diary) } \\
\text { effects of current medication, diet and fluids } \\
\text { on bladder function } \\
\text { how to self-monitor symptoms and interpret } \\
\text { their bladder diary } \\
\text { purpose of bladder training } \\
\text { o how bladder training works } \\
\text { o the rise and de-escalation of the sensation of } \\
\text { urgency, sometimes known as the 'urge } \\
\text { wave' [36] } \\
\text { o the staged approach to bladder training } \\
\text { the need for active involvement, commitment } \\
\text { and ongoing motivation } \\
\text { psychological strategies to support success } \\
\text { o realistic expectations about the efforts } \\
\text { required and the potential challenges } \\
\text { expected outcomes }\end{array}$ & $\begin{array}{l}\text { Education is central to all behavioural therapy } \\
\text { [15,24] and forms the first phase of all bladder } \\
\text { training programmes [24] } \\
\text { Understanding the differences between their } \\
\text { own bladder function and normal bladder } \\
\text { function enables a person to identify where } \\
\text { they can change their behaviour [37] } \\
\text { - Understanding the purpose and content of } \\
\text { bladder training allows a person to actively } \\
\text { engage }[24,38,39]\end{array}$ & $\begin{array}{l}\text { Details of verbal education } \\
\text { and written information } \\
\text { provided are recorded in } \\
\text { bladder training plan, with } \\
\text { time frames and methods } \\
\text { for providing information. }\end{array}$ \\
\hline$>$ & $\begin{array}{l}\text { An initial bladder training programme and voiding } \\
\text { intervals are agreed and implemented based on } \\
\text { the person's baseline voiding diary information and } \\
\text { individual goals. } \\
\text { Bladder training is usually implemented during } \\
\text { waking hours only } \\
\text { Voiding intervals are set in accordance with the } \\
\text { person's preference for a standardised bladder drill } \\
\text { or individually tailored bladder training schedule: } \\
\text { o If standardised a fixed (or pre-determined) } \\
\text { voiding schedule of half-hourly or hourly voids } \\
\text { is implemented for an agreed time period. } \\
\text { Once achieved, this schedule is increased by } \\
\text { a pre-determined duration of } 5 \text {, 10, } 15 \text { or } 30 \\
\text { minutes at each progression point. } \\
\text { If tailored, individualised voiding intervals are } \\
\text { implemented based on the person's average } \\
\text { voiding interval calculated from their voiding } \\
\text { diary. Progression time to prolong voiding } \\
\text { intervals is negotiated on an individual basis } \\
\text { e.g. increase by } 5,10,15,30 \text { minutes per } \\
\text { week. } \\
\text { The health care practitioner regularly reviews the } \\
\text { bladder training programme with the person to } \\
\text { determine specific voiding interval progression in }\end{array}$ & $\begin{array}{l}\text { Educating patients to resist urgency } \\
\text { sensations and postpone voiding using a } \\
\text { scheduled voiding programme is believed to } \\
\text { result in an increased functional bladder } \\
\text { capacity and reduced urgency, and ultimately } \\
\text { reduces voiding frequency [25,29] } \\
\text { At this point in time, evidence about bladder } \\
\text { training is limited to daytime. In general, } \\
\text { bladder training is not performed during } \\
\text { sleeping hours as it may interrupt the quality } \\
\text { and duration of a person's sleep. } \\
\text { No evidence is available on how to select the } \\
\text { most effective voiding programme - } \\
\text { individually tailored or standardised. Limited } \\
\text { evidence suggests both approaches are } \\
\text { effective [9,41] } \\
\text { Successful and sustained increases in } \\
\text { voiding intervals may build and embed new } \\
\text { voiding habits but evidence is lacking on } \\
\text { psychological and physiological effects } \\
\text { Positive reinforcement of progress towards } \\
\text { goal attainment is a fundamental part of } \\
\text { bladder training [15] Frequent patient contact } \\
\text { is essential to achieve this [25]. }\end{array}$ & 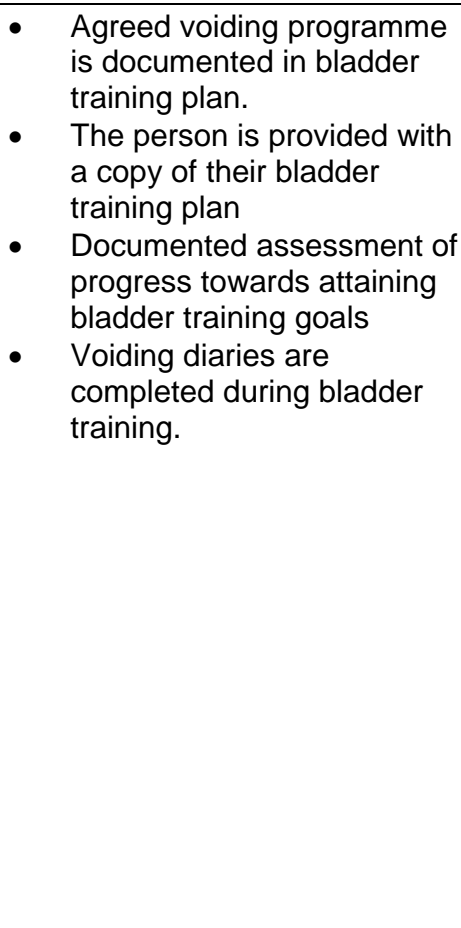 \\
\hline
\end{tabular}


line with their goals. Voiding diary data and selfreport inform this process.

New continence skills are developed in the form of personalised urge suppression strategies.

Urge suppression or deferment involves:

o relaxation - the person is instructed to stop, sit down if possible, relax their whole body, in particular their abdomen and focus on slow, controlled breathing.

o pelvic floor muscle contraction - the person completes 5-8 fast pelvic floor muscle contractions, without increasing their intraabdominal pressure.

o distraction techniques - mental activities that demand cognitive attention and concentration are used to distract the person from their sensation of urgency and desire to void.

o The individual should decide what will work for them. Examples include: counting backwards from 100 in 7's, identifying different girl's names through the alphabet, singing out loud, word searches/crossword puzzles, digital games, reading, making lists.

o Use of self-affirming statements such as 'I can control my bladder' and 'I don't have to go now'

o apply perineal pressure - sit on a hard surface, rolled towel or stimulate foot sensation using toe curls and heel pressure until the urgency subsides.

Urgency sensation may subside within 1-2 minutes.

When urgency is controlled, and if voiding is programme, the person is encouraged to walk to the toilet at a normal pace. permitted according to the bladder training

- $\quad$ Bladder training uses techniques to enable urgency to be resisted, voiding postponed, voiding intervals to be prolonged, functional bladder capacity increased and frequency and urgency reduced as a result [20].

- Urgency may induce feelings of anxiety or panic, which affects ability to concentrate $[23,31]$. Hyperventilation and contraction of abdominal muscles are associated with anxiety and panic and raise intra-abdominal pressure [23]. The role of cognition and emotion in suppressing the urge to void is not well established, however deep breathing is hypothesised to induce subsidence of bladder urgency sensation and relaxation of detrusor [23]

- Rushing to the toilet raises intra-abdominal pressure and exposes the individual to visual cues that can trigger incontinence [23]

- Rapid pelvic floor muscle contractions can inhibit detrusor contraction and diminish urgency [36]

- Attention is diverted away from the sensation of urgency when concentrating on competing mental activities, which allows the urgency to subside temporarily giving the person time to walk to the bathroom at a normal pace [23]

- $\quad$ Learning to 'stop \& squeeze' [40] and experiencing success positively reinforces the chosen urge suppression technique.

- Well-designed controlled trials of urge suppression have shown mean frequency of weekly urinary incontinence episode reductions of $50-80 \%$ in women $[29,42,43]$

- $\quad$ The MOTIVE trial [44] showed urge suppression techniques were as effective as antimuscarinics in men without bladder outlet obstruction who continue to have $\mathrm{OAB}$ symptoms with alpha-blocker therapy.

The health care practitioner positively reinforces the person's bladder control skills and improved and/or prolonged bladder control. Individuals are actively encouraged and supported to o self-monitor their:

- relaxation capability and capacity to control their response to urgency and fear of incontinence episodes

- duration of urge suppression

- intensity of urgency sensations

- number of incontinence episodes

- $\quad$ reduction in negative voiding habits such as 'just in case' or anticipatory voiding

- $\quad$ progress toward achieving a normal bladder pattern

o self-determine their:

- $\quad$ progression time e.g. increasing urge suppression/voiding delay time

- decisions about when to increase their urge suppression/voiding delay time.

o self-affirm their:
- $\quad$ Operant learning through experiencing positive effects of bladder training builds confidence in individual ability to control bladder [45]

- $\quad$ Self-monitoring refers to monitoring of specific physiologic parameters or symptoms of a health condition [46]

- Two components of self-monitoring include:

- awareness of bodily symptoms, sensation, daily activities, voiding habits and cognitive processes

- $\quad$ measurement including reading and recording results eg using a bladder diary

- $\quad$ Together these inform understanding and provide information for action by the individual, in consultation with health care practitioners [31]

- Supporting an individual's autonomy and competence development fosters motivation towards bladder training, ongoing engagement and adherence [34]

- Conscious awareness of automatic thoughts through examining them can enable them to be self-managed. Techniques can be learned
- $\quad$ Education about urge suppression strategies and person's selected techniques is documented in bladder training plan
- $\quad$ Record of progress is documented.

- Use of written bladder training programme adherence records, agreed by person and health care practitioner. 


\begin{tabular}{|c|c|c|}
\hline $\begin{array}{l}\text { - Use of personally meaningful self- } \\
\text { coping statements such as 'I don't } \\
\text { have to go now; I can wait'; 'I am in } \\
\text { control of my bladder' }\end{array}$ & $\begin{array}{l}\text { to change incontinence-related cognitions, } \\
\text { emotions and behaviours from negative to } \\
\text { positive [31] } \\
\text { Use of positive self-coping statements } \\
\text { (verbally out loud is better) can interrupt } \\
\text { automatic thoughts and act as a counter } \\
\text { directive e.g. 'I can wait 2-3 minutes to go to } \\
\text { the bathroom or 'I can conquer this feeling, I } \\
\text { do not have to go now' rather than 'I can't } \\
\text { wait, I have to go now' [30] }\end{array}$ & \\
\hline \multicolumn{3}{|l|}{ Evaluation } \\
\hline $\begin{array}{l}\text { Regular contact between the person and the } \\
\text { healthcare practitioner is made during the bladder } \\
\text { training programme to review progress, assess } \\
\text { adherence, provide positive reinforcement and adjust } \\
\text { voiding programme/intervals. At the end of the } \\
\text { bladder training programme a range of person- } \\
\text { focused outcomes are assessed. These may include: } \\
\text { - } \quad \text { perceptions of bladder condition } \\
\text { and improvement } \\
\text { influence of bladder on daily } \\
\text { activities } \\
\text { - } \quad \text { satisfaction with bladder training } \\
\text { tolerability of bladder training and } \\
\text { adherence } \\
\text { frequency and severity of urgency } \\
\text { and incontinence episodes } \\
\text { improvements in lower urinary tract } \\
\text { - symptoms } \\
\text { voiding interval changes } \\
\text { lifestyle changes } \\
\text { - changes in quality of life } \\
\text { change in body-worn absorbent } \\
\text { product use }\end{array}$ & $\begin{array}{l}\text { - Frequent patient contact is a fundamental } \\
\text { component of successful bladder training [18] } \\
\text { and the most intensive supervision by a } \\
\text { healthcare practitioner as is possible is } \\
\text { recommended }[2,3] \text {. } \\
\text { - Feedback and reinforcement of overall } \\
\text { changes from start of training programme } \\
\text { confirms effectiveness and motivates } \\
\text { continued adherence to maintain progress } \\
\text { made }[21,25,41]\end{array}$ & $\begin{array}{l}\text { - Voiding diaries completed } \\
\text { and repeated during the } \\
\text { bladder training programme } \\
\text { [29] } \\
\text { Use of validated, } \\
\text { standardised symptom and } \\
\text { quality of life tools, to } \\
\text { ensure robust measurement } \\
\text { and ability to compare } \\
\text { outcomes in different } \\
\text { populations, study settings } \\
\text { etc. } \\
\text { Measures are recorded } \\
\text { before and after the bladder } \\
\text { training programme. } \\
\text { Goals are reviewed and } \\
\text { level of achieving them is } \\
\text { periodically evaluated }\end{array}$ \\
\hline
\end{tabular}

\section{Appendix 1: Consensus Statement on Bladder Training}




\section{Assessment}

Healthcare practitioners conduct an assessment of the person's bowel symptoms to ensure the cause and type of bowel dysfunction is identified prior to recommending a bowel training programme Current lifestyle and risk factors for bowel dysfunction (e.g. aggravating foods, medication side effects) are assessed.

Underlying physiological abnormalities are excluded prior to recommending a bowel training programme

The person's suitability to undertake bowel training is assessed including:

- $\quad$ potential for benefit.

- functional ability to use the toilet/toilet aid

- cognitive capacity

- motivation to undertake and adhere to a personalised bowel training programme

- expectations of treatment

- has ability to voluntarily contract pelvic floor muscles
Assessment is essential to establish the cause of the faecal incontinence/ bowel dysfunction [27]

- $\quad$ Bowel training is any programme that includes scheduled attempts to defecate [48]

- Conservative management, including bowel training, is recommended when faecal incontinence is mild or moderate [27]

- Active participation is essential to modify behaviour and develop central control over the bowel [31]

- Individual beliefs and expectations are fundamental to a person's behaviour and indicates their likely participation and adherence [32]
A complete assessment includes:

- Documented comprehensive individual assessment including lifestyle factors

- Diagnosed functional bowel disorder.

- Completed bowel diary (minimum 5-7 days)

- Individual expectations of bowel training and planned lifestyle changes documented $[5,47]$

\section{Planning}

$>$ The person's goals for bowel training are established with the healthcare practitioner, e.g., a reduction in the frequency and severity of symptoms; the ability to go out and socialise; reduced carer burden such as laundering soiled clothing and linens, decreased socialization and travel, cost of absorbent products etc.

The practitioner develops or structures the person's bowel training programme in collaboration with them, taking into account the following factors before commencing the programme:

- the frequency of evacuation

- $\quad$ the duration of the full bowel training programme in weeks/months

- $\quad$ the indicators of improvement

- $\quad$ the types of urgency suppression techniques the person will use (where appropriate)

- methods to normalise and regulate stool consistency

- $\quad$ the method the person will use to selfmonitor their progress e.g. bowel diaries

- lifestyle changes are described

\section{Intervention}

The healthcare practitioner ensures the bowel training programme is structured and supervised. The programme duration will vary according to the person's progress and goals.
- It is important for healthcare practitioners to assist individuals to set specific goals that are personal, and realistic [27]

- Working towards a specific goal improves motivation and performance $[33,34]$
- Personal goals and indicators of success documented in bowel training plan.

- Review dates and end of bowel training programme dates are specified
The healthcare practitioner provides adults undertaking bowel training with verbal and written information and education on:

- normal bowel function

- how faecal incontinence occurs
Regular practice of skills to maintain continence is essential to maintain performance $[5,39]$

- Intensive supervision by a healthcare practitioner improves the likelihood of positive outcomes [5]
- $\quad$ Documented bowel training programme including mode and frequency of contact between person and healthcare practitioner in bowel training plan.

- Contact appointments agreed

- Education is central to all behavioural therapy $[15,24]$

- $\quad$ Understanding the differences between their own bowel function and normal bowel function enables a person to identify where they can change their behaviour [27]
- $\quad$ Details of verbal education and written information provided are recorded in bowel training plan. 
- $\quad$ factors affecting bowel functioning including diet and dietary fibre, fluids, smoking, exercise, psychological/emotional status and environment

- $\quad$ medication and laxatives.

- $\quad$ purpose of bowel training and how it works

- $\quad$ the need for active involvement, commitment and ongoing motivation by the person

- $\quad$ psychological strategies to support success

- use of containment products during bowel training

- $\quad$ realistic expectations about the efforts required and the potential challenges

- $\quad$ expected outcomes
- Expert opinion suggests that understanding the purpose and content of bowel training allows a person to actively engage $[48,49]$

- A single nurse-led education session improved post-stroke bowel function [50]: 4-5 nurse-led education sessions reduced faecal incontinence by more than half in one randomised controlled trial [51]
The person's bowel diary (minimum 5-7 days) is interpreted jointly by the person and the healthcare practitioner to identify individual bowel function and patterns and align with agreed goals.

The healthcare practitioner offers the person a bowel training programme that includes information about:

- optimal time of day for evacuation

- frequency of evacuation attempts, e.g., daily, alternate days, three times per week

- optimal type and amount of food intake

- optimal type and amount of fluid intake

- individual advice on smoking cessation

- use of drugs, dietary fibre, or rectal irrigation for faecal incontinence; antidiarrheal drugs or stool bulking agents may be used to establish and maintain a normal stool consistency and frequency; laxatives, suppositories, enemas or transanal irrigation may be used to empty the rectum to avoid leakage.

An external anal sphincter (EAS) and pelvic floor muscle exercise programme, tailored to the lifestyle and needs of the person is agreed with the healthcare practitioner. This will include specific exercises aimed at improving strength, speed and endurance of the external anal sphincter and pelvic floor muscle contraction and relaxation. Concerns/anxieties affecting the person's psychological/ emotional state are actively screened for and managed.

The healthcare practitioner ensures the person can use effective evacuation techniques:

- $\quad$ Correct positioning on the toilet - may involve use of footstools and leaning forward to increase hip flexion, straighten the anorectal angle, and ensure stability of sitting position.

- Allowing sufficient time to fully empty bowel

- Ensuring privacy and no interruptions

- Attention to privacy and comfort measures e.g. toilet temperature, noise and odour reduction
- $\quad$ Bowel habit training is undertaken to establish regular, effective and predictable bowel evacuation patterns and adherence to a bowel routine.

- $\quad$ Peristaltic colon contractions increase in frequency following awakening from sleep and meals (gastro-colic reflex). The period after breakfast is the best time for scheduled defaecation [48] or after evening meal.

- Many foods and fluids are known to influence stool consistency and bowel patterns [27]

- Educating patients to resist bowel urgency sensations and postpone evacuation has not yet been subject to rigorous research [5]

- Randomized controlled trials show that dietary fibre supplementation decreased faecal incontinence $[55,56,57]$

Observed effects of dietary fibre were reduced faecal incontinence frequency and firming of stool consistency in some studies $[55,56,57]$

- Observational studies show that dietary fibre supplementation decreased urgency faecal incontinence [11]

- Observational studies show transanal irrigation decreased fecal incontinence [5]

- Reported exercise regimens for external anal sphincter and pelvic floor muscles vary widely in terms of the type, number and intensity of exercises taught: e.g. maximum contraction held for increasing duration up to 10 seconds (for strength); submaximal contraction held for several seconds (for endurance); fast, short contractions (for speed); how many exercises per day and in what pattern and duration over which the exercises should be performed [7]

- Psychological and emotional concerns are both a cause and a consequence of faecal incontinence and should be actively screened for [27]

- Increased hip flexion in squatting straightens the anorectal angle and reduces strain associated with defecation [52]
- $\quad$ An agreed bowel routine is documented in the bowel training plan

- $\quad$ The person is provided with a copy of their bowel training plan

- Regular bowel diaries are recorded during training programme.

- Documented review of progress towards attaining bowel training goals 
The healthcare practitioner encourages the person to develop individualised urge suppression strategies:

When the person feels the urge to defeacate they are encouraged to suppress the urge using the techniques below until the sensation is reduced sufficiently to allow them to get to a toilet without rushing. Once they are in the toilet they are encouraged to wait for a minute or so before actually sitting on the toilet to open their bowels.

They gradually increase the amount of time they wait before they use the toilet.

Urge suppression or deferment involves:

o relaxation - the person is advised to stop, relax their whole body, in particular their abdomen and focus on slow, controlled breathing.

o external anal sphincter and pelvic floor muscle_contraction - the person completes 5-8 fast contractions, without increasing their intra-abdominal pressure.

o distraction techniques - mental activities that demand cognitive attention and concentration will distract the person from their sensation of urgency and desire to evacuate. The individual should decide what will work for them (different techniques may be used at different times). Examples include: counting backwards from 100 in 7's (or 5's for older adults), identifying girl's names through the alphabet, singing out loud, word searches/crossword puzzles, digital games, reading, making lists.

o applying perineal pressure - sit on a hard surface, rolled towel

Bowel urgency sensation may subside within 1-2 minutes. When urgency is controlled, encourage person to walk to the toilet at a normal pace.

The healthcare practitioner positively reinforces the person's continence skills and improved and/or prolonged bowel control.

Individuals are actively encouraged and supported to:

o self-monitor their:

- perceived capability to relax - to stop what they are doing, take slow, deep breaths, relax their body especially their abdomen and not rush to the toilet until the urgency sensation has diminished

- duration of urge suppression

- intensity of urgency sensations

- number of faecal incontinence episodes

- reduction in negative evacuation habits such as prolonged or frequent toilet use

- progress toward achieving a normal bowel pattern

- lifestyle changes

o self-determine their:

- progression time e.g. increased urge suppression/delay time

- decisions about when to increase duration of their urge suppression/delay time.
Bowel training uses techniques to enable urgency to be resisted and evacuation to be postponed until a suitable time and place can be reached. However, teaching people to resist bowel urgency sensations and postpone evacuation has not yet been subject to rigorous research [5]

- Bowel urgency may induce feelings of anxiety or panic, which affects ability to concentrate [31]. Hyperventilation and contraction of abdominal muscles are associated with anxiety and panic and raise intra-abdominal pressure, thus increasing the sense of urgency to evacuate.

- Waiting in the toilet before sitting down to evacuate their bowel reinforces the person's ability to hold off and the success of urge suppression in a safe environment.

- A study of internal anal sphincter pressure wave patterns in 72 adults showed relaxation breathing promotes more regular pressure wave patterns and may aid in reducing fecal urgency and incontinence [53]

- $\quad$ Learning to 'stop \& squeeze' [40] and experiencing success positively reinforces the chosen urge suppression technique and may lead to improved control of faecal urgency/incontinence.

- Explanations for bladder training effects include diverting attention away from the urgency sensation using competing mentally demanding activities [23]. This proposed mechanism may be equally applicable to bowel training.
- $\quad$ Education about urge suppression strategies and person's selected techniques is documented in bowel training plan

- Documented assessment of feelings (anxiety and panic) related to bowel training.
- $\quad$ Operant learning through experiencing positive effects of bowel training may build confidence in bowel control ability. Positive reinforcement of progress towards goal attainment is a fundamental part of bowel training [54]

- $\quad$ Self-monitoring refers to monitoring of specific physiologic parameters or symptoms of a health condition [46]. Two components of selfmonitoring include:

i) awareness of bodily symptoms, sensation, daily activities, voiding habits and cognitive processes and

ii) measurement including reading and recording results

- $\quad$ Together these inform understanding and provide information for action by the individual, in consultation with health care practitioners [31]

- Supporting an individual's autonomy and competence development will foster motivation towards bowel training, ongoing engagement and adherence [34]

- Conscious awareness of automatic thoughts through examining them can enable them to be self-managed. Techniques can be learned to change incontinence-related cognitions,
- $\quad$ Record of progress is documented.

- Use of written bowel training programme records, agreed by person and health care practitioner.

- Documented patient concerns/anxieties that affect the patients psychological/ emotional state and how they are being managed 
o use of personally meaningful selfcoping statements such as 'I don't have to go now; I can wait'; 'I am in control of my bowel' emotions and behaviours from negative to positive [31]

- Use of positive self-coping statements (verbally out loud is better) can interrupt automatic thoughts and act as a counter directive e.g. 'I can wait 2-3 minutes to go to the bathroom or 'I can conquer this feeling, I do not have to go now' rather than 'I can't wait, I have to go now' [11]

\section{Evaluation}

Regular contact between the person and the healthcare practitioner is made during the bowel training programme to review progress, assess adherence, provide positive reinforcement and adjust schedules.

At the end of the bowel training programme a range of person-focused outcomes are assessed. These may include:

o perceptions of bowel condition and any improvements/changes

o satisfaction with bowel training

o tolerability of bowel training processes and adherence to recommended programme

0 frequency and severity of bowel symptoms including urgency and incontinence episodes

o evacuation intervals

o lifestyle changes

o quality of life

o change in body-worn absorbent product use (e.g., decrease in number)
- $\quad$ Feedback and reinforcement of overall changes from start of training programme confirms effectiveness and motivates continued adherence to maintain progress made [36]

- Positive reinforcement of progress towards goal attainment is a fundamental part of bowel training [54]
- $\quad$ Bowel diaries completed during the training programme.

- Use of validated, standardised symptom and quality of life tools, to ensure robust measurement and ability to compare outcomes in different populations, study settings etc.

- Measures are recorded before and after the bowel training programme.

- $\quad$ Goals are reviewed and level of achieving them is periodically evaluated

\section{Appendix 2: Consensus Statement on Bowel Training}

